\title{
An Assessment of the Perceived Effectiveness of Credit Risk Management Strategies Adopted by Microfinance Institutions in the Sekondi -Takoradi Metropolis, Ghana
}

\author{
John Nana Ekow Baiden \\ Faculty of Business Studies, Takoradi Technical University, P O Box 256, Takoradi, Ghana \\ *E-mail of the corresponding author: jonylepoks@yahoo.com
}

\begin{abstract}
The purpose of the study was to assess the perceived effectiveness of credit risk management strategies (CRMS) adopted by microfinance institutions (MFIs) in the Sekondi-Takoradi Metropolis (STM), Ghana. Descriptive survey design was adopted for the study. The population was 261 . The sample size for the study was 158 key staff of the various MFIs selected purposively. These key staff were credit officers, finance staff, and managers of the various MFIs. Questionnaire with a reliability coefficient of 0.87 was the instrument used to collect the data. Descriptive statistical tools such as means and standard deviations were used to analyse the data. The findings show that there are meaningful and appropriate credit policies and procedures used by MFIs in STM. However, the effectiveness of CRMS adopted by MFIs in STM is not quite good. Also, credit control processes adopted by the MFIs are not quite adequate as expected. It was recommended that administrators of MFIs in the metropolis should enhance their respective institution's credit policies and procedures, especially the appraisal of client process. This will create room for the institutions to have credit policies and procedures that allow the institution to identify and analyse all loss exposures, and measure such loss exposures appropriately.
\end{abstract}

Keywords: Credit control process, Credit policies, Credit procedures, Credit risk management

DOI: $10.7176 / \mathrm{RJFA} / 11-6-15$

Publication date:March $31^{\text {st }} 2020$

\section{Introduction}

Credit risk can be seen as the potential that a borrower or counterpart will fail to meet its obligations in accordance with agrees terms (Kibui \& Moronge, 2014). It involves inability or unwillingness of a customer or counterparty to meet commitments in relation to lending, trading, hedging, settlement and other financial transactions. Microfinance institutions (MFIs) ability to compete, survive and perform better depends mostly on their capability to manage credit risk appropriately. Credit risk management is a structured approach to managing uncertainties through risk assessment, developing strategies to manage it, and mitigation of risk using managerial resources (Acharya, Hasan \& Saunders, 2015). The strategies include transferring to another party, avoiding the risk, reducing the negative effects of the risk, and accepting some or all of the consequences of a particular risk.

The goal of credit risk management is to maximize firms' risk-adjusted rate of return by maintaining credit risk exposure within acceptable parameters which in turn increase their performance. According to Gerhard (2015), the effective management of credit risk is a critical component of a comprehensive approach to risk management and essential to the long-term success of any Microfinance Institution (MFI).

In Ghana, MFIs remain the most dynamic force and agent of economic growth and development of the country. They help in providing financial services to at least 60 percent of entrepreneurs in the informal sector (Abor \& Quartey, 2010). Evidence has shown that MFIs in Ghana over the years have contributed greatly in the area of provision of funds to the development of Small and Medium Enterprises (SMEs) which has helped in boosting the overall employment and production of goods and services (Abor \& Quartey, 2010). Therefore, managing credit risk in MFIs is critical for the survival, growth and good performance of these institutions. In these institutions, the issue of Credit Risk Management Strategies (CRMS) is of great concern because of the higher levels of perceived risks in the industry. The difficulties faced by MFIs as a result of ineffective CRMS has resulted in a situation where many of them tend to collapse few years after they have been established or at best, perform poorly in subsequent years (Samolyk, 2015).

\subsection{Statement of the problem}

Generally, the accomplishment of MFIs to a great extent relies on the viability of their CRMS in light of the fact 
that these institutions create the greater part of their pay from premium earned on loans (Gerhard, 2015). A sound CRMS is critical for the survival and growth of the micro finance sector. The successes of MFIs largely depend on the effectiveness of their CRMS because these institutions generate most of their income from interest earned on loans extended to SMEs. The Bank of Ghana (BoG) yearly supervision report, 2016, demonstrated high rate of loan threat in the financial sector which is mirrored in the growing levels of non-performing loans by MFIs in the last 10 years. This situation has antagonistically affected MFIs viability (BoG, 2017). Also, this pattern not just debilitates the practicality and supportability of MFIs, it obstructs the accomplishment of the objectives for which MFIs were planned, which are to give credit to SMEs, the rural unbanked populace, and extending the financing role in the conventional financial sector (BoG, 2016; 2017).

A study on CRMS and its effectiveness among MFIs is an area of substantial concern by many practitioners and researchers. Some studies looking at CRMS concentrated essentially on credit card models used by banks and their effect on non-performing loans and productivity (Acharya et al., 2015; Mugoya, 2014). Also, most of the studies examining MFIs' CRMS focused on commercial banks, and on developed countries whose cultural dynamics are different from ours (Frank, Simon \& Josephine, 2014; Samolyk, 2015). In addition, only few concentrated on MFIs with regard to the effectiveness of their CRMS. Therefore, it is appropriate for this study to assess the perceived effectiveness of CRMS adopted by MFIs in the Sekondi-Takoradi Metropolis (STM). This is in acknowledgment of the fact that MFIs play significant roles in the Ghanaian economy, and therefore, it is necessary to carry out this study within the cultural context of Ghana.

\subsection{Objectives of the study}

The main objective of the study was to assess the perceived effectiveness of CRMS adopted by MFIs in STM in the Western Region of Ghana. Specifically, the study:

1. examines the credit policies and procedures used by MFIs in STM;

2. assesses the perceived effectiveness of CRMS adopted by MFIs in STM;

3. examines the credit control process adopted by MFIs in STM.

\subsection{Significance of the study}

The findings of the study would help management of MFIs to put in place measures that addressed the problems relating to CRMS. It would also assist managers of MFIs to identify other factors that will help them to reduce or eliminate the rate of credit defaults by their customers, thereby ensuring sound, secured and profitable MFI in Ghana. This would enhance the ability to play their intermediation role effectively and to prevent their demise. Also, the findings of the study will be vital on giving exact confirmation about the connection between CRMS and loan performance of MFIs in STM. This is so in light of the fact that without such proof no solid techniques can be drawn with regard to the advancement of MFIs. The work will again serve as a reference material for the microfinance sector in making decisions concerning ways of developing accurate and effective CRMS.

\subsection{Delimitation}

The study was delimited to MFIs in STM. Specifically, the study looked at the perceived effectiveness of CRMS adopted by selected MFIs in STM. As a result, 10 MFIs was selected for the study. Again, the study was delimited to employees who are involved in management, credit and finance decisions within the institutions. In relation to the variables of the study, the study was delimited to procedures in credit risk management, challenges in credit risk management, and the perceived effectiveness of credit risk management.

\subsection{Literature Review}

Generally, banks and MFIs are affected by many types of risk. However, the main type that has to be measured and monitored closely is credit risk. Mismanagement of this type of risk has been found to bring about the occurrence of non-performing loans and ultimately the bankruptcy of financial institutions (Samolyk, 2015). This situation is causing major financial crises in various corners of the world, affecting both developed and undeveloped economies (Samolyk, 2015).

According to Saani (2012), very low deposits and high default rates have plunged some MFIs into serious liquidity problems, culminating in the erosion of public confidence in these institutions. He indicated further that a combination of poor lending practices and ineffective monitoring of credit facilities extended to customers has 
contributed to high loan delinquency in some of these institutions. Gisemba (2012) also posits that most MFIs have now adopted various approaches in screening and analysing risk before awarding credit to client. These interventions are done to minimize loan loss. They include establishing capacity, conditions, use of collateral, borrower screening, and use of risk analysis in attempt to reduce and manage credit risks. Gisemba added that for MFIs to manage credit risks effectively they must minimize loan defaulters, cash loss, and ensure that the institutions perform better by increasing their respective returns on assets.

However, both Migiri (2014) and Morduch (2015) assert that once one incorporates risk and financial capital into the production frontier techniques, the estimate financial returns to scale, largely through capital savings, are considerably larger than when risk and capital are ignored. Morduch (2015) further posits that the larger institutions holding company are better diversified across regions and loan types, such diversification reduced the volatility of MFIs' stock returns and improved the loan performance. Nevertheless, spreading out financial operations over a broader space does not come without costs. Ross, Westerfield and Jordan (2018) posit that the period for which credit is advanced is affected by credit risk, collateral value, competition in the market, and size of client's account. Ross et al. added that in order to evaluate a customer as a potential borrower, MFIs employ the 5Cs model due to its role in increasing loan performance once they get to know their customers better. These 5Cs are character, capacity, collateral, capital and condition.

Micro finance institutions are well known for providing financial help to the unbanked sections of the society. Since microfinance is a system that distributes small loans to small business, usually those in the informal sector, in order for them to generate more income and expand their small businesses, it has the ability to lessen poverty as well as promote entrepreneurship, social and economic development in poor communities (Devi, 2017). MFIs inherent characteristic of targeting those in the informal sector expose them to various kinds of risks. However, effective lending policies on the part of MFIs play significant roles in their credit risk management. In line with the lending policies, it was inferred that indeed MFIs do have competent personnel for appraising prospective borrowers and also that collateral was material in lending policies (BoG, 2017). Therefore, there is the need for MFIs to adopt appropriate corporate financing system to help them manage risk which will in turn help boost their performance significantly.

\subsection{Research Methods}

The study adopted the quantitative approach in its data gathering and analysis. Also, the descriptive survey design was adopted for this study. The target population constituted all the 140 licensed MFIs in STM (NBSSI, 2019). According to the National Board for Small Scale Industries (NBSSI, 2019), there were 140 registered and licensed MFIs in Ghana as at the time of the study. However, only 87 were active, and they were more accessible to the researcher. The study considered key staff of the various MFIs operating in the metropolis. These include credit officers, finance staff, and managers of the various MFIs in the area. The accessible population was estimated to be 261 since each MFI has at least one manager and two credit officers, or risk/financial analysts averagely. These groups of respondents were considered because they were more exposed to the credit management and assessment of the institution and they understand better the dynamics of CRMS of the institutions.

\subsection{Sample and sampling procedure}

The sample size for the study was 158 key staff of the various MFIs in the metropolis. The sample size used was based on the recommended formula of Slovin's (as cited in White, 2015). The formula is $\mathrm{n}=\mathrm{N} \div\left[1+\mathrm{N}\left(\mathrm{e}^{2}\right)\right]$, where $\mathrm{n}$ is the sample size, $\mathrm{N}$ is the population size, and e is the level of precision.

$\mathrm{n}=\mathrm{N} \div\left(1+\mathrm{N}\left[\mathrm{e}^{2}\right]\right) \quad \mathrm{n}=\quad 261 \div\left(1+261[0.05]^{2}\right)=157.9 \approx 158$

The purposive sampling procedure was used to select all the key staff (credit officers, finance staff, and managers) of the MFIs selected. The study made use of this sampling technique because the researcher wanted to capture knowledge rooted in a particular form of expertise. This technique enabled the researcher to become better informed about the topic at hand since credit officers, finance staff and managers of the various selected MFIs were more knowledgeable in the subject matter. The selected credit officers, risk analysts, financial analysts, and the managers of the selected MFIs were able to provide data that allowed the researcher to tackle the objectives of the study as expected.

\subsection{Results and Discussion}

Based on the four-point numerical scale used, the study adopted mathematical approximation techniques to 
interpret the mean scores. Thus Strongly Agree (3.5 - 4.0), Agree (2.5 - 3.4), Disagree (1.5 - 2.4), and Strongly Disagree $(1-1.4)$. The results are presented as follows:

\subsection{Credit policies and procedures used by MFIs in STM}

The rational of the first specific objective of the study was to examine the credit policies and procedures used by MFIs in STM. Fourteen close-ended items were used to collect data on this issue. The results are presented in Table 1. As indicated in the table, respondents strongly agreed that there are regulations on a complete loan application document in their respective institutions (Mean $=3.75, \mathrm{SD}=0.86$ ), and limitations given to customers with regard to the credit policies and procedures of the institutions (Mean $=3.74, \mathrm{SD}=0.89$ ). Respondents further agreed strongly that debts are categorised based on different criteria in the institutions (Mean $=3.66, \mathrm{SD}=0.89$ ), and also there are assessment process and approval criteria in place (Mean $=3.54, \mathrm{SD}=0.98)$.

Table 1: Respondents' View on Credit Policies and Procedures of MFIs

\begin{tabular}{lll}
\hline Statements on credit policies and procedures & Mean & SD \\
\hline There are regulations on a complete loan application document & 3.75 & 0.86 \\
There are limitations given to customers & 3.74 & 0.89 \\
Debts are categorised based on different criteria & 3.66 & 0.89 \\
There is an assessment process and approval criteria in place & 3.54 & 0.98 \\
Provisions are made for loan losses & 3.23 & 0.93 \\
Duties of each credit person or sub-unit are clearly described & 2.94 & 1.00 \\
There are post-approval supervision and collection controls & 2.76 & 0.88 \\
There are procedures to counter overdue debts and recovery & 2.58 & 0.91 \\
Provisions are made to encounter loan loss & 2.57 & 0.92 \\
The time period for loan repayment is well defined and applied & 2.21 & 0.89 \\
Loan pricing (risk-based) and maturities are well implemented & 2.19 & 0.87 \\
Collaterals from the debtors are constantly reviewed & 2.13 & 0.89 \\
There are credit rating systems of each customer & 1.58 & 0.91 \\
Credit is approved by only the lending authorities & 1.34 & 1.01 \\
\hline
\end{tabular}

Source: Field data, $2019 \quad$ Where SD = Standard Deviation

$(\mathrm{N}=141)$

Results from Table 1 further show that respondents agreed that provisions are made for loan losses in their respective institutions (Mean $=3.23, \mathrm{SD}=0.93$ ) and also duties of each credit person or sub-unit are clearly described $($ Mean $=2.94, \mathrm{SD}=1.00)$. Similarly, respondents were of the view that there are post-approval supervision and collection controls (Mean $=2.76, \mathrm{SD}=0.88$ ), and also procedures to counter overdue debts and recovery (Mean $=2.58, \mathrm{SD}=0.91)$. Again, respondents agreed that contingency measures are put in place by the institutions to deal with or encounter loan loss (Mean $=2.57, \mathrm{SD}=0.92)$.

Nevertheless, as indicated in Table 1, respondents disagreed that the time period for loan repayment is well defined and applied $($ Mean $=2.21, \mathrm{SD}=0.89)$, loan pricing (risk-based) and maturities are well implemented $($ Mean $=$ $2.19, \mathrm{SD}=0.87$ ), and collaterals from the debtors are constantly reviewed (Mean $=2.13, \mathrm{SD}=0.89$ ). Also, respondents disagreed strongly that there are credit rating systems of each customer $($ Mean $=1.58, \mathrm{SD}=0.91)$, and that credit is approved by only the lending authorities (Mean $=1.34, \mathrm{SD}=1.01)$. This means that in some of the MFIs in STM, not only lending officers or staff approved credit.

The findings that emerged from Table 1 show that in relation to credit policies and procedures of MFIs, those in STM exhibit some significant level of it. As indicated, the institutions give credit limitations to customer (E.g., amount they can lend, time period for payment etc.), they make provisions for loan losses, roles of credit officers are clearly defined, and all loans pass through assessment process and approval criteria. Also, there is post-approval supervision and collection controls in these institutions. Even though respondents indicated that the credit policies and procedures of MFIs in the metropolis are in good shape, there are some of the policies and procedures that the 
institutions are not adhering to as expected. This means that MFIs in STM use client appraisal in credit management to a moderate extent. Further the study established that credit policies and procedures of the institutions with regard to client appraisal is a viable strategy for credit. However, collateral from the debtors are not reviewed constantly (Acharya et al., 2015). This means, appraising clients, failure to assess customer's capacity to repay may results in loan defaults, client appraisal considers the character of the customers seeking credit facilities and that MFIs in STM have competent personnel for carrying out client appraisal.

Also, the results show that there are some weaknesses in the credit policies and procedures of MFIs in STM in the area of effective loan pricing, loan time period, review of collaterals, and credit rating systems. Also, MFIs in the metropolis have relatively meaningful credit policies and procedures that allow them to make sure that it gives credit only to customers who are able to pay on scheduled date (Devi, 2017). One may therefore, say that MFIs in STM use credit policies and procedures to a moderate extent. This creates room for them to use meaningful credit risk control in their credit management. However, the finding that credit is not approved by only the lending authorities may mean that there is the need for credit committees' involvement in making decisions regarding loans According to Devi (2017), these are essential in reducing default/credit risk which in the long run enhances credit management of the institutions.

\subsection{Assessing the perceived effectiveness of CRMS Adopted by MFIs in STM}

The rationale for the second objective was to assess the effectiveness of CRMS adopted by MFIs. The views of the respondents are presented in Table 2. As shown in the table, respondents perceived the reduction in loan processing effort (Mean $=3.79, \mathrm{SD}=0.91$ ) and risk-based appraisal and sanctions $(\mathrm{Mean}=2.98, \mathrm{SD}=0.88)$ as CRMS that MFIs in STM have adopted effectively. However, respondents were of the view that independence of risk assessment from loan sanction $($ Mean $=2.32, \mathrm{SD}=1.02)$, restriction on responsibility for credit approval and reviews $($ Mean $=2.27, \mathrm{SD}=1.10)$, internal audits $($ Mean $=2.18, \mathrm{SD}=0.93)$, regular rating reviews $(\mathrm{Mean}=2.16$, $\mathrm{SD}=0.95)$, and focusing on weak/problem loans (Mean $=2.13, \mathrm{SD}=0.97$ ) were not some of the CRMS adopted effectively by MFIs in STM.

Table 2: Perceived Effectiveness of CRMS Adopted by MFIs

\begin{tabular}{lll}
\hline Statements on effectiveness of credit risk management & Mean & SD \\
\hline Reduction in loan processing effort & 3.79 & 0.91 \\
Risk-based appraisal and sanctions & 2.98 & 0.88 \\
Independence of risk assessment from loan sanction & 2.32 & 1.02 \\
Restriction on responsibility for credit approval and reviews & 2.27 & 1.10 \\
Internal audits & 2.18 & 0.93 \\
Regular rating reviews & 2.16 & 0.95 \\
Focus on weak/problem loans & 2.13 & 0.97 \\
Independent loan reviews & 1.77 & 0.86 \\
Reduction of subjectivity in credit ratings & 1.64 & 0.81 \\
Regular discussions and feedback & 1.59 & 1.13 \\
Multi-tier credit approval processes & 1.30 & 0.91 \\
Source: Field data, 2019 Where SD = Standard Deviation & $(\mathrm{N}=141)$
\end{tabular}

Similarly, independent loan reviews (Mean $=1.77, \mathrm{SD}=0.86)$, reduction of subjectivity in credit ratings $($ Mean $=$ $1.64, \mathrm{SD}=0.81)$, regular discussions and feedback $($ Mean $=1.59, \mathrm{SD}=1.13)$, and multi-tier credit approval processes $($ Mean $=1.30, \mathrm{SD}=0.91)$ were some of the CRMS adopted by MFIs in STM that were not perceived to be effectively implemented. As indicated in Table 2, in the assessment of the perceived effectiveness of CRMS of MFFs in STM, it was revealed that the MFIs had written policies that guided them on credit granting and its related risks such that they have been able to reduce their loan processing effort and also have put in place effective riskbased appraisal and sanctions. The views of the respondents may mean that MFIs do not periodically reviewed and consistently applied their credit policies in order to reflect the institutions' risk tolerance expected. 
Generally, the views of the respondents mean that techniques used for the management of credit risk by MFIs in STM within the study period were not relatively ineffective. The findings may be seen as bad news to the industry since effectiveness of CRMS is very essential to the institutions because it enables them to know whether they are achieving good financial performances in relation to credit risk management.

The findings support the submission of Saani (2012) who indicated that very low deposits and high default rates have plunged some MFIs into serious liquidity problems, culminating in the erosion of public confidence in these institutions. Saani indicated further that a combination of poor lending practices and ineffective monitoring of credit facilities extended to customers has contributed to high loan delinquency in some MFIs. According to Saani (2012), these challenges are happening as a result of poor CRMS adopted by these MFIs. Like other financial institutions, MFIs face risks that they must manage effectively to be successful. If they fail to manage their risks well, they are likely not to meet their social and financial objectives. This may mean that lack ineffective CRMS of MFIs in STM have helped altogether to the financial downturn in Ghana with regard to the microfinance industry.

\subsection{Credit control process adopted by MFIs in STM}

Examining credit control process adopted by MFIs in STM was the third objective of the study. The views of the respondents are presented in Table 3. The results show that in relation to credit control process adopted by MFIs in STM, signing of the credits and collateral agreement (Mean $=3.60, \mathrm{SD}=0.98$ ), giving creditors reminder letters (Mean $=3.27, \mathrm{SD}=0.83)$, compliance with internal guidelines $($ Mean $=2.97, \mathrm{SD}=0.92)$, establishing payment guidelines $(\mathrm{Mean}=2.92, \mathrm{SD}=0.85)$, and developing an account receivable section $(\mathrm{Mean}=2.64, \mathrm{SD}=0.98)$ are some of the processes adopted by the institutions. However, respondents disagreed that improvement of internal control system $($ Mean $=2.27, \mathrm{SD}=0.86)$, effective monitoring $($ Mean $=2.09, \mathrm{SD}=0.97)$, and seeking or initiating legal processes $($ Mean $=1.58, \mathrm{SD}=0.87$ ) should be part of credit control process to be adopted by MFIs in STM. Similarly, respondents strongly disagreed that using the collateral security to defray the indebtedness $($ Mean $=1.38$, $\mathrm{SD}=0.91)$ and providing incentive for prompt payment (Mean $=1.29, \mathrm{SD}=0.97)$ were some of the credit control processes that are adopted by MFIs in STM. This shows that credit control processes adopted by MFIs are not quite adequate as expected.

Table 3: Respondents' Views on Credit Control Process Adopted by MFIs

\begin{tabular}{lll}
\hline Statements on credit control process adopted by MFIs & Mean & SD \\
\hline Signing of the credits and collateral agreement & 3.60 & 0.98 \\
Reminder letters & 3.27 & 0.83 \\
Compliance with internal guidelines & 2.97 & 0.92 \\
Establish payment guideline & 2.92 & 0.85 \\
Develop an account receivable section & 2.64 & 0.98 \\
Improve internal control system & 2.27 & 0.86 \\
Effective monitoring & 2.09 & 0.97 \\
Seek or initiate legal processes & 1.58 & 0.87 \\
Use the collateral security to defray the indebtedness & 1.38 & 0.91 \\
Provide incentive for prompt payment & 1.29 & 0.97 \\
\hline
\end{tabular}

Source: Field data, $2019 \quad$ Where SD = Standard Deviation

$(\mathrm{N}=141)$

The results from Table 3 may mean that MFIs must work within the ambient of a clear, well-laid out credit granting criteria and processes. According to Gerhard (2015), MFIs ought to set up a plainly characterised process with the sole aim for approving new credit and in addition the change, recommencement and re-funding of operational loan facilities. The findings also show that the credit control process adopted by MFIs is not quite adequate. The findings are in line with that of Devi (2017) who found out that the credit control processes adopted by MFIs do not adequately help in guiding the institutions to take appropriate credit decision. He added that most of the MFIs credit control process lacked basic credit management essentials like credit delivery process, credit portfolio mix, basis of pricing, management of problem loans among others to adequately make them robust. The findings may imply that MFIs need to enunciate a credit control processes that enables them to monitor quality of the credit 
portfolio on day-to-day basis and take remedial measures as and when any deterioration occurs. Such processes would enable MFIs to ascertain whether loans are being serviced as per facility terms, the adequacy of provisions, the overall risk profile is within limits established by management and compliance of regulatory limits.

\section{Conclusion}

Based on the findings, the following conclusions were drawn. There are meaningful and appropriate credit policies and procedures used by MFIs in STM. These include customer credit limitations, loan losses provisions, staff role clarity, effective appraisal and approval process, post-approval supervision and collection controls, review of collaterals, and provisions to encounter loan loss. However, the effectiveness of CRMS adopted by MFIs in STM is not quite good. Also, credit control processes adopted by the MFIs are not quite adequate as expected. Even though MFIs in STM are face with many challenges regarding their CRMS, the various risk management strategies adopted by these institutions has become a universal phenomenon. When these strategies are adapted appropriately, the institutions become more effective and efficient in dealing with credit which in the long run can help enhance their performance.

\section{Recommendations}

Based on the findings and conclusions of the study, it is recommended to administrators of MFIs in STM to ensure that they enhance their respective institution's credit policies and procedures, especially the appraisal of client process. They can do that through formulation of policies that details ways of capturing all the credit risk. This will create room for the institutions to have credit policies and procedures that allows the institution to identify and analyse all loss exposures and measure such loss exposures. Also, it recommended to the Chairman of the various aboard of the MFIs to ensure that credit unit of each MFI draft a point by point appraisal of budgetary reasonability through utilisation of devices like proportion appraisal to judge the engaging quality and reliability, liquidity levels, productivity, benefit, influence of a given customer before financing. This will make their CRMS more effective.

\section{References}

Abor, J., \& Quartey, P. (2010), "Issues in SME development in Ghana and South Africa", International Research Journal of Finance and Economics, 39(2), 29-41.

Acharya, V. V., Hasan, I., \& Saunders, A. (2015), “The effects of focus and diversification on bank risk and return: Evidence from individual bank loan portfolios”. Mimeo, New Jersey: Institute of Technology.

Bank of Ghana (BoG, 2016), “A new capital adequacy framework for MFIs”, Accra: BoG.

Bank of Ghana (BoG, 2017). Annual supervision report, 2016: First draft. Unpublished report, BoG, Accra-Ghana.

Cohen, L., Manion, L., \& Morrison, K. (2011), "Research methods in education” ( $6^{\text {th }}$ ed.), New York: Routledge.

Devi, P. S. (2017), "Credit risk management practices of micro finance institutions in Ethiopia: A brief literature review”, SSRG International Journal of Economics and Management Studies (SSRG-IJEMS), 4(1), 10-16.

Frank, B., Simon, G., \& Josephine, M. (2014), "Risk management practices adopted by financial firms in Malta. Managerial Finance”, 40, 587-612.

Gerhard, S. (2015). "Risk management and value creation in financial institutions ” ( $4^{\text {th }}$ ed.), New York: John Wiley and Sons.

Gisemba, P. N. (2012), "The relationship between credit risk management practices and financial performance of SACCOs in Kenya”, Unpublished master's thesis, School of Business, University of Nairobi, Nairobi.

Kibui, N., \& Moronge, M. (2014), "Effects of credit risk management on financial performance of SACCOS: A case study of Harambee SACCO”, International Journal of Social Sciences and Project Planning Management, l(3), 157-172.

Migiri, D. O. (2014), “Credit management models: A case of banks in Kenya”, Unpublished thesis, University of Nairobi, Nairobi.

Morduch, J. (2015), “The microfinance promise”, Princeton: Princeton, University Press.

Mugoya, M. A. (2014), "Uganda commercial bank non-performing loans: The role of the lending process", 
Unpublished master's thesis, Makerere University, Kampala.

National Board for Small Scale Industries (NBSSI, 2019), "Making micro finance institutions more productive”, Accra: NBSSI.

Ross, S. A., Westerfield, R. W., \& Jordan, B. D. (2018), “Essentials of corporate finance” (2 ${ }^{\text {nd }}$ ed.), New York: McGraw-Hill Companies Inc.

Saani, A. E. (2012), "Silver jubilee celebration of microfinance institutions activities in Ghanaian economy", Unpublished report, NBSSI, Accra.

Samolyk, M. P. (2015), "Diversification in micro financing and its implications for MFI portfolio choice and performance”, New York: Federal Reserve Bank of New York.

White, C. J. (2015), "Research: A practical guide” (3 ${ }^{\text {rd }}$ ed.), Pretoria: Ithuthuko Investments Publishing. 